\title{
Protective effects of fruit-juices on sperm viability of West African Dwarf goat bucks during cryopreservation
}

\author{
J.O. Daramola ${ }^{1,6}$, E.O. Adekunle ${ }^{1}$, O.M. Onagbesan ${ }^{1}$, O.E. Oke ${ }^{1}$, A.O. Ladokun ${ }^{1}$, J.A. Abiona ${ }^{1}$, \\ M.O. Abioja ${ }^{1}$, I.K. Oyewusi ${ }^{2}$, J.A. Oyewusi ${ }^{2}$, O.A Isah $^{3}$, O.M. Sogunle ${ }^{4}$, M.A. Adeleke \\ ${ }^{1}$ Department of Animal Physiology, Federal University of Agriculture Abeokuta, Nigeria. \\ ${ }^{2}$ College of Veterinary Medicine, Federal University of Agriculture Abeokuta, Nigeria. \\ ${ }^{3}$ Department of Animal Nutrition, Federal University of Agriculture Abeokuta, Nigeria. \\ ${ }^{4}$ Animal Production \& Health, Federal University of Agriculture Abeokuta, Nigeria. \\ ${ }^{5}$ Animal Breeding \& Genetics, Federal University of Agriculture Abeokuta, Nigeria.
}

\begin{abstract}
The present study was conducted to determine the effects of adding fruit-juices to semen extenders on viability of buck spermatozoa during cryopreservation in two studies. Pooled semen samples obtained from West African Dwarf (WAD) goat bucks were diluted with Tris-egg yolk based extenders. In study I, the diluted semen samples were supplemented with orange (Citrus sinensis), cucumber (Cucumis sativus) and pineapple (Ananas comosus) juices $(2.5,5,7.5$ and $10 \mathrm{ml} / 100 \mathrm{ml})$. In study II, the diluted semen samples were supplemented with $5 \mathrm{ml} / 100 \mathrm{ml}$ of different combinations of fruitjuices consisting of pineapple and orange juices (TEYPO) at a 1:1 ratio, pineapple and cucumber juices (TEYPC) at a 1:1 ratio, orange and cucumber juices (TEYOC) at a 1:1 ratio, and pineapple, orange and cucumber juices (TEYPOC) at a 1:1:1 ratio, respectively. The diluted semen samples were cryopreserved and thereafter evaluated for sperm viability parameters. The extenders supplemented with 7.5 and $10 \%$ orange, and $10 \%$ pineapple had higher $(\mathrm{P}<0.05)$ motility compared to the control. There was higher $(\mathrm{P}<0.05)$ acrosome integrity in extenders supplemented with orange and pineapple at all levels compared to the control while cucumber at $10 \%$ had higher $(\mathrm{P}<0.05)$ acrosome integrity compared to other levels and the control. The extenders supplemented with cucumber, orange and pineapple had higher $(\mathrm{P}<0.05)$ membrane integrity compared to the control except at $7.5 \%$ of extender supplemented with cucumber. Similarly, the extenders supplemented with cucumber, orange and pineapple had lower $(\mathrm{P}<0.05)$ sperm abnormality compared to the control. The extenders supplemented with cucumber, orange and pineapple at $2.5,10$ and $7.5 \%$ respectively had lower $(\mathrm{P}<0.05)$ concentrations of MDA compared to other levels and the control. There was higher motility and acrosome integrity in extenders supplemented with different combinations of fruit-juices $(\mathrm{P}<0.05)$ compared to the control. TEYPC had higher $(\mathrm{P}<0.05)$ membrane integrity and lower $(\mathrm{P}<0.05)$ concentrations of MDA compared to the control. The
\end{abstract}

findings revealed that extenders supplemented with orange and pineapple at $10 \%$ consistently improved motility, acrosome integrity and membrane integrity, and reduced sperm abnormality compared to the control while no particular combination of these fruit-juices was consistently superior in all the parameters.

Keywords: antioxidants, buck sperm, extender, freezing, sperm parameters.

\section{Introduction}

The West African Dwarf (WAD) goats (Capra hircus) possess certain valuable traits that confer adaptation to endemic trypanosomiasis challenge and hot humid tropics (Daramola and Adeloye, 2009). Some breeds that do not have adaptive traits, however, are gradually replacing them. There is need to preserve semen from the breed such that it could be used for subsequent artificial insemination over an extended period of time. Artificial insemination with preserved semen is a viable option for genetic upgrading of this breed. The survival of sperm after collection in seminal plasma for longer periods during preservation at low temperatures requires dilution with appropriate extender in order to maintain viability of spermatozoa. Regardless of the extender constituents, however, viability of spermatozoa deteriorates at low temperatures during storage. Sperm cells are subject to oxidative stress resulting from lipid peroxidation, which can lead to reduced sperm viability and fertility (Donghue and Donoghue, 1997). Although semen contains antioxidants that counteract the damaging effects of lipid peroxidation and prevent excessive peroxide formation (Lewis et al., 1997), the endogenous antioxidative capacity of semen may be insufficient during storage (Maxwell and Salamon, 1993). In vitro studies suggested that the addition of some antioxidants to semen extenders could improve the motility and survival of spermatozoa (Sanchez-Partida et al., 1997; Krzyosiak et al., 2000; Bilodeau et al., 2002). Fruits are good sources of natural antioxidants, containing many different antioxidant components (Cao et al., 1996; 
Wang et al., 1996; Velioglu et al., 1998). These antioxidants include carotenoids, vitamins, phenolic compounds and flavonoids and have proved to function as singlet and triplet oxygen quenchers, free radical scavengers and peroxide decomposers (Larson, 1988). In addition, natural foods and food-derived antioxidants such as vitamin $\mathrm{C}, \mathrm{E}$ and phenolic phytochemicals have been reported to act as chemo-preventive agents against oxidative damage (Kiwon et al., 2003; Ondei et al., 2009). Cucumber (Cucumis sativus), pineapple (Ananas comosus) and orange (Citrus sinensis) are fruit-rich natural antioxidants renowned for their high concentrations of these vitamins and other antioxidants (Cutler et al., 2008). Improved survival rate of spermatozoa preserved with tomato juice at $5^{\circ} \mathrm{C}$ was observed in African catfish (Clarias gariepinus; Adeyemo et al., 2007). In addition, Al-Daraji (2012) reported the protective effect of orange juice on spermatozoa against the harmful effects of lipid peroxidation of white layer cocks' semen stored for up to $72 \mathrm{~h}$. Daramola and Adekunle (2015) recently observed improved progressive motility, acrosome and membrane integrities, reduced abnormalities and MDA following supplementation of extenders with pineapple and cucumber juices during refrigeration of semen obtained from WAD goat bucks. However, there is limited data regarding freezing or cryopreservation of semen obtained from WAD goat bucks with fruit-juice. The aim of the present study was, therefore, to determine the effects of adding different levels and/or combinations of fruit-juices obtained from cucumber, pineapple and orange to semen extenders on sperm viability of WAD goat bucks during cryopreservation.

\section{Materials and Methods}

The experiment was carried out at the Goat Unit of the Teaching and Research Farm at the Federal University of Agriculture in Abeokuta, Nigeria, which falls within $7^{0} 10^{\prime} \mathrm{N}$ and $3^{0} 2^{\prime} \mathrm{E}$ and altitude $76 \mathrm{~m}$ above sea level. It lies within the South-Western part of Nigeria with a prevailing tropical climate, a mean annual rainfall of $1,037 \mathrm{~mm}$ and average temperature of $34.7^{\circ} \mathrm{C}$. Six WAD bucks that responded well to semen collection by artificial vagina were selected from a group of twenty intact WAD bucks aged 2.5-3 years. The animals were kept under intensive management and maintained under a uniform and constant nutritional regime with concentrate feed supplemented with guinea grass (Panicum maximum).

\section{Juice preparation}

The fruit-juice was prepared according to the procedure by Adeyemo et al. (2007) with some modifications as follows: fresh cucumber, pineapple and orange were washed thoroughly using distilled water. The fruits were first peeled (pineapple and orange) and thereafter cut into pieces and the seeds were removed (cucumber and orange) and then the fruit were blended for five minutes, placed in a sieve and pressure was applied manually to squeeze the juice out from the blended fruits. The juices collected from each fruit were put in separate plastic test tubes and centrifuged at 3000 $\mathrm{x} g$ for $20 \mathrm{~min}$. The supernatant fluid obtained was decanted into a clean beaker and used immediately for the experiment.

\section{Semen collection, dilution and storage}

Two studies were carried out to determine the protective effects of fruit-juices obtained from cucumber, pineapple and orange on sperm viability. Semen samples were collected from six WAD goat bucks with the aid of an artificial vagina and pooled. A total of six semen samples (each semen sample originating from six bucks) showing $>80 \%$ motility was pooled to minimize individual differences (Bucak and Tekin, 2007). Semen samples were diluted at $32^{\circ} \mathrm{C}$ in a two-step process (Watson, 1995; Purdy, 2006) with a Tris-egg yolk based extender composed of 2 fractions. The fraction 1 solution contained Tris-hydroxymethylaminomethane (2.42 g), citric acid (1.36 g), glucose $(1 \mathrm{~g})$, penicillin $(0.028 \mathrm{~g})$, egg yolk $(20 \mathrm{ml})$ and distilled water up to $100 \mathrm{ml}$ as control ( $\mathrm{pH}$ 6.91). The fraction 2 solution had the same composition as fraction 1 solution with the addition of $14.0 \%$ glycerol $(\mathrm{v} / \mathrm{v})$.

\section{Study I}

The effect of adding different levels of fruitjuices on sperm viability of WAD goat bucks during cryopreservation was determined in study I. Each pooled ejaculate was split into 13 equal aliquots, diluted with the fraction 1 solution and supplemented with orange, cucumber and pineapple juices at 2.5, 5, 7.5 and $10 \mathrm{ml} / 100 \mathrm{ml}$ of the diluents respectively at a final concentration of $277 \times 10^{6} \mathrm{sperm} / \mathrm{ml}$. Fraction 2 solution was subsequently added. The $\mathrm{pH}$ of the fruit-juice extenders (pineapple juice: 7.14, orange juice: 6.98 and cucumber juice: 6.98) was determined using a digital $\mathrm{pH}$ metre. Diluted semen samples were then loaded into $2 \mathrm{ml}$ plastic straws, sealed with polyvinyl, cooled to $4^{\circ} \mathrm{C}$ at a rate of $0.25^{\circ} \mathrm{C} / \mathrm{min}$ and equilibrated at this temperature for $10 \mathrm{~min}$ in TYFSF Refrigerated Incubator (Model:SPX-7OB III, Hebei, China). Subsequently, the straws were placed on a rack $4 \mathrm{~cm}$ above liquid nitrogen in the vaporous phase for $10 \mathrm{~min}$ before plunging them directly and quickly into liquid nitrogen for 10 days, and thereafter evaluated for sperm viability parameters.

\section{Study II}

The effect of adding different combinations of fruit-juices on sperm viability of WAD goat bucks 
during cryopreservation was determined in study II. Each pooled ejaculate was split into 5 equal aliquots and diluted with the fraction 1 solution (fraction 1 and 2 solutions had the same composition as in study I). Different combinations of fruit-juices (each at $5 \mathrm{ml} / 100$ $\mathrm{ml}$ ) consisting of pineapple and orange juices (TEYPO) at a 1:1 ratio, pineapple and cucumber juices (TEYPC) at a 1:1 ratio, orange and cucumber juices (TEYOC) at a 1:1 ratio, and pineapple, orange and cucumber juices (TEYPOC) at a 1:1:1 ratio, respectively, were added to the diluted semen samples. Fraction 2 solution was subsequently added. Diluted semen samples were cryopreserved and thereafter evaluated for viability parameters.

\section{Sperm motility}

Sperm motility was determined as described by Bearden and Fuquay (1997). Briefly, semen samples were thawed in a Clifton Water bath (Model: 74178 by Nickel Electro Ltd, Weston-S-Mare Somerset, England) at $37^{\circ} \mathrm{C}$ and accessed for sperm motility using a Celestron PentaView microscope (LCD-44348 by RoHS, China) at 400X magnification. A $5 \mu \mathrm{l}$ semen sample was placed directly on a heated microscope slide and overlaid with a $22 \times 22 \mathrm{~mm}$ cover slip. For each sample, five microscopic fields were examined to observe progressively motile spermatozoa that moved forward in essentially a straight line and the mean of the five successive evaluations was recorded as the final motility score.

\section{Acrosome integrity}

The percentage of spermatozoa with intact acrosome was determined according to Ahmad et al. (2003). Briefly, $50 \mu 1$ of each semen sample was added to a $500 \mu \mathrm{l}$ formalin citrate solution $(96 \mathrm{ml} 2.9 \%$ sodium citrate, with $4 \mathrm{ml} 37 \%$ formaldehyde) and mixed carefully. A small drop of the mixture was placed on a microscope slide and a total of 200 spermatozoa were counted in at least three different microscopic fields for each sample, using Celestron PentaView LCD microscope (400X magnification). Intactness of acrosome characterized by normal apical ridge of spermatozoa was recorded.

\section{Sperm membrane integrity}

Hypo-osmotic swelling test (HOST) assay as described earlier (Jeyendran et al., 1984) was used to determine sperm membrane integrity. This was done by incubating $10 \mu \mathrm{l}$ semen in $100 \mu \mathrm{l}$ Hypo-osmotic solution (fructose and sodium citrate) at $37^{\circ} \mathrm{C}$ for $30 \mathrm{~min}, 0.1 \mathrm{ml}$ of the mixture was spread over a warmed slide, covered with a cover slip and observed under a Celestron PentaView LCD digital microscope (400X magnification). Two hundred spermatozoa were counted for their swelling characterized by coiled tail, indicating intact plasma membrane.

\section{Sperm morphology}

Sperm abnormality was evaluated as described by Bearden and Fuquay (1997) with the use of eosinnigrosin smears. A thin smear of a mixture of semen and eosin-nigrosin solution were drawn across the slide and dried. Two hundred and forty spermatozoa were counted and morphologically abnormal spermatozoa with defects in the head, midpiece and tail were observed (400X magnification) with a Celestron PentaView LCD digital microscope.

\section{Malondialdehyde (MDA) concentrations}

MDA concentration as index of lipid peroxidation in the stored semen was measured in a thiobarbituric acid reactive substances (TBARS) according to Yagi (1998). For this assay, $0.1 \mathrm{ml}$ of sperm suspension was incubated with $0.1 \mathrm{ml}$ of $150 \mathrm{mM}$ Tris- $\mathrm{HCl}(\mathrm{pH} 7.1)$ for $20 \mathrm{~min}$ at $37^{\circ} \mathrm{C}$. Subsequently, 1 $\mathrm{ml}$ of $10 \%$ trichloroacetic acid (TCA) and $2 \mathrm{ml}$ of $0.375 \%$ thiobarbituric acid was added followed by incubation in boiling water for $30 \mathrm{~min}$. Thereafter, it was centrifuged for $15 \mathrm{~min}$ at $3000 \mathrm{x}$ g inside the blank tube and the absorbance was read with UV spectrophotometer (SW7504 model by Surgifriend Medicals, England) at $532 \mathrm{~nm}$. The MDA concentration was calculated as follows: The concentration of MDA $(\mathrm{nmol} / \mathrm{ml})=\mathrm{AT}-\mathrm{AB} / 1.56 \times 10^{5}$; where $\mathrm{AT}=$ the absorbance of the sample, $\mathrm{AB}=$ the absorbance of the blank, $1.56 \times 10^{5}$ molar absorptivity of MDA.

\section{Statistical analysis}

Data obtained were subjected to a $3 \times 5$ factorial arrangement in study I, and one-way analysis of variance in study II using SAS 1999. Duncan Multiple Range Test (Duncan, 1955) was used to separate significantly different means. The models used are shown below:

\section{Study I}

$\mathrm{Y}_{\mathrm{ijk}}=\mu+\mathrm{J}_{\mathrm{i}}+\mathrm{L}_{\mathrm{j}}+\mathrm{JL}_{\mathrm{ij}}+\Sigma_{\mathrm{ijk}}$

Where

$\mathrm{Y}_{\mathrm{ijk}}=$ Dependent variable

$\mu=$ population mean

$\mathrm{J}_{\mathrm{i}}=\mathrm{i}^{\text {th }}$ effect due to juice type, $\mathrm{i}=1,2,3$

$L_{j}=j^{\text {th }}$ effect due to level, $j=0,2.5 .5,7.5,10$

$\mathrm{JL}_{\mathrm{ij}}=$ interaction between juice type and level

$\Sigma_{\mathrm{ijk}}=$ experimental error

\section{Study II}

$\mathrm{Y}_{\mathrm{ij}}=\mu+\mathrm{J}_{\mathrm{i}}+\Sigma_{\mathrm{ij}}$

Where

$\mathrm{Y}_{\mathrm{ij}}=$ Dependent variable 
$\mu=$ population mean

$\mathrm{J}_{\mathrm{i}}=\mathrm{i}^{\text {th }}$ effect due to juice combinations, $\mathrm{i}=1,2,3,4,5$

$\Sigma_{\mathrm{ij}}=$ experimental error

\section{Results}

The viability parameters of spermatozoa in trisegg yolk extenders supplemented with fruit-juices during cryopreservation are presented in Tables 1, 2, 3, 4, 5 and 6 . The extenders supplemented with orange at 7.5 and $10 \%$ had higher $(\mathrm{P}<0.05)$ motility compared to the control (Table 1). There was higher $(\mathrm{P}<0.05)$ motility in the extender supplemented with $10 \%$ pineapple compared to the control (Table 1). There was higher $(\mathrm{P}<0.05)$ acrosome integrity in the extender supplemented with cucumber at $10 \%$ compared to other levels and the control (Table 2). Acrosome integrity was higher $(\mathrm{P}<0.05)$ in extenders supplemented with orange and pineapple at all levels compared to the control (Table 2). The extenders supplemented with cucumber, orange and pineapple had higher $(\mathrm{P}<0.05)$ membrane integrity compared to the control except at $7.5 \%$ of the extender supplemented with cucumber (Table 3). Similarly, extenders supplemented with cucumber, orange and pineapple had lower $(\mathrm{P}<0.05)$ sperm abnormality compared to the control (Table 4). Extenders supplemented with cucumber, orange and pineapple at 2.5, 10 and $7.5 \%$ respectively had lower $(\mathrm{P}<0.05)$ concentrations of MDA compared to other levels and the control (Table 5). The extenders supplemented with different combinations of fruit-juices had higher $(\mathrm{P}<0.05)$ motility and acrosome integrity compared to the control (Table 6). There was higher $(\mathrm{P}<0.05)$ membrane integrity and lower $(\mathrm{P}<0.05)$ concentrations of MDA in TEYPC compared to the control (Table 6).

Table 1. Mean ( \pm SEM) progressive motility (\%) of buck spermatozoa cryopreserved with Tris-egg yolk extenders supplemented with fruit-juices.

\begin{tabular}{lccccc}
\hline Parameters & $0 \%$ & $2.5 \%$ & $5 \%$ & $7.5 \%$ & $10 \%$ \\
\hline Cucumber & $35.20 \pm 4.08^{\mathrm{ab}}$ & $29.80 \pm 1.96^{\mathrm{b}}$ & $41.20 \pm 3.81^{\mathrm{ab}}$ & $47.60 \pm 5.89^{\mathrm{a}}$ & $48.800 \pm 9.16^{\mathrm{a}}$ \\
Orange & $35.20 \pm 4.08^{\mathrm{c}}$ & $39.00 \pm 3.11^{\mathrm{bc}}$ & $29.20 \pm 3.69^{\mathrm{c}}$ & $53.20 \pm 1.83^{\mathrm{a}}$ & $48.00 \pm 3.99^{\mathrm{ab}}$ \\
Pineapple & $35.20 \pm 4.08^{\mathrm{c}}$ & $48.60 \pm 5.38^{\mathrm{abc}}$ & $53.00 \pm 6.24^{\mathrm{ab}}$ & $46.00 \pm 2.45^{\mathrm{bc}}$ & $62.20 \pm 4.10^{\mathrm{a}}$ \\
\hline
\end{tabular}

$\overline{\mathrm{a}, \mathrm{b}, \mathrm{c}}$ Values in the same row with different superscripts differ significantly $(\mathrm{P}<0.05)$.

$\mathrm{SEM}=$ Standard Error of mean.

Table 2. Mean $( \pm$ SEM) acrosome integrity (\%) of buck spermatozoa cryopreserved with Tris-egg yolk extenders supplemented with fruit-juices.

\begin{tabular}{lccccc}
\hline Parameters & $0 \%$ & $2.5 \%$ & $5 \%$ & $7.5 \%$ & $10 \%$ \\
\hline Cucumber & $33.25 \pm 2.29^{\mathrm{b}}$ & $34.50 \pm 2.22^{\mathrm{b}}$ & $28.00 \pm 1.58^{\mathrm{b}}$ & $33.25 \pm 1.44^{\mathrm{b}}$ & $38.00 \pm 0.91^{\mathrm{a}}$ \\
Orange & $33.25 \pm 2.29^{\mathrm{c}}$ & $42.50 \pm 1.26^{\mathrm{ab}}$ & $39.00 \pm 1.08^{\mathrm{b}}$ & $46.00 \pm 1.29^{\mathrm{a}}$ & $44.00 \pm 2.27^{\mathrm{ab}}$ \\
Pineapple & $33.25 \pm 2.29^{\mathrm{b}}$ & $47.25 \pm 1.38^{\mathrm{a}}$ & $49.25 \pm 0.48^{\mathrm{a}}$ & $45.75 \pm 0.85^{\mathrm{a}}$ & $48.75 \pm 0.95^{\mathrm{a}}$ \\
\hline
\end{tabular}

${ }^{\bar{a}, b, c}$ Values within the same row with different superscripts differ significantly $(\mathrm{P}<0.05)$; SEM $=$ Standard Error of mean.

Table 3. Mean ( \pm SEM) membrane integrity (\%) of buck spermatozoa cryopreserved with Tris-egg yolk extenders supplemented with fruit-juices.

\begin{tabular}{lccccc}
\hline Parameters & $0 \%$ & $2.5 \%$ & $5 \%$ & $7.5 \%$ & $10 \%$ \\
\hline Cucumber & $20.00 \pm 1.08^{\mathrm{bc}}$ & $27.50 \pm 1.19^{\mathrm{a}}$ & $26.75 \pm 1.25^{\mathrm{a}}$ & $22.75 \pm 0.75^{\mathrm{b}}$ & $26.25 \pm 0.95^{\mathrm{a}}$ \\
Orange & $20.00 \pm 1.08^{\mathrm{c}}$ & $40.75 \pm 0.48^{\mathrm{a}}$ & $39.25 \pm 1.11^{\mathrm{a}}$ & $34.25 \pm 2.06^{\mathrm{b}}$ & $38.00 \pm 1.96^{\mathrm{ab}}$ \\
Pineapple & $20.00 \pm 1.08^{\mathrm{c}}$ & $39.50 \pm 1.04^{\mathrm{ab}}$ & $41.00 \pm 1.47^{\mathrm{a}}$ & $37.50 \pm 0.65^{\mathrm{ab}}$ & $37.25 \pm 0.95^{\mathrm{ab}}$ \\
\hline a,b,c Values within the same row with different superscripts differ significantly $(\mathrm{P}<0.05) ;$ SEM $=$ Standard Error of \\
mean.
\end{tabular}

Table 4. Mean ( \pm SEM) percent abnormality (\%) of buck spermatozoa cryopreserved with Tris-egg yolk extenders supplemented with fruit-juices.

\begin{tabular}{lccccc}
\hline Parameters & $0 \%$ & $2.5 \%$ & $5 \%$ & $7.5 \%$ & $10 \%$ \\
\hline Cucumber & $8.00 \pm 1.00^{\mathrm{a}}$ & $5.00 \pm 0.58^{\mathrm{b}}$ & $1.67 \pm 0.88^{\mathrm{c}}$ & $4.00 \pm 1.00^{\mathrm{bc}}$ & $2.00 \pm 0.57^{\mathrm{c}}$ \\
Orange & $8.00 \pm 1.00^{\mathrm{a}}$ & $2.33 \pm 0.67^{\mathrm{b}}$ & $2.00 \pm 0.00^{\mathrm{b}}$ & $2.00 \pm 0.57^{\mathrm{b}}$ & $1.00 \pm 0.57^{\mathrm{b}}$ \\
Pineapple & $8.00 \pm 1.00^{\mathrm{a}}$ & $4.67 \pm 1.20^{\mathrm{b}}$ & $0.33 \pm 0.33^{\mathrm{c}}$ & $2.33 \pm 0.67^{\mathrm{bc}}$ & $2.00 \pm 0.58^{\mathrm{bc}}$ \\
\hline
\end{tabular}

$\overline{\mathrm{a}, \mathrm{b}, \mathrm{c}}$ Values within the same row with different superscripts differ significantly $(\mathrm{P}<0.05)$; SEM $=\mathrm{Standard} \mathrm{Error} \mathrm{of}$ mean. 
Daramola et al. Effects of fruit-juices on cryopreserved spermatozoa.

Table 5: Mean $( \pm$ SEM) MDA concentration $(\mathrm{nmol} / \mathrm{ml})$ of buck spermatozoa cryopreserved with Tris-egg yolk extenders supplemented with fruit-juices.

\begin{tabular}{lccccc}
\hline Parameters & $0 \%$ & $2.5 \%$ & $5 \%$ & $7.5 \%$ & $10 \%$ \\
\hline Cucumber & $0.13 \pm 0.00^{\mathrm{b}}$ & $0.08 \pm 0.02^{\mathrm{c}}$ & $0.31 \pm 0.32^{\mathrm{a}}$ & $0.14 \pm 0.12^{\mathrm{b}}$ & $0.12 \pm 0.12^{\mathrm{b}}$ \\
Orange & $0.13 \pm 0.00^{\mathrm{b}}$ & $0.17 \pm 0.11^{\mathrm{a}}$ & $0.11 \pm 0.10^{\mathrm{b}}$ & $0.14 \pm 0.06^{\mathrm{b}}$ & $0.07 \pm 0.02^{\mathrm{c}}$ \\
Pineapple & $0.13 \pm 0.00^{\mathrm{b}}$ & $0.15 \pm 0.12^{\mathrm{a}}$ & $0.11 \pm 0.09^{\mathrm{b}}$ & $0.08 \pm 0.07^{\mathrm{c}}$ & $0.12 \pm 0.07^{\mathrm{b}}$ \\
\hline
\end{tabular}

$\overline{\mathrm{a}, \mathrm{b}, \mathrm{c}}$ Values within the same row with different superscripts differ significantly $(\mathrm{P}<0.05)$; SEM $=\mathrm{Standard} \mathrm{Error} \mathrm{of}$ mean; MDA = Malondialdehyde.

Table 6: Mean $( \pm$ SEM) viability parameters of buck spermatozoa cryopreserved with combinations of different fruit-juices.

\begin{tabular}{lccccc}
\hline Parameters & TEY & TEYOC & TEYPO & TEYPC & TEYPOC \\
\hline Motility (\%) & $19.20 \pm 1.83^{\mathrm{d}}$ & $82.00 \pm 7.84^{\mathrm{a}}$ & $56.67 \pm 11.30^{\mathrm{bc}}$ & $46.67 \pm 3.33^{\mathrm{c}}$ & $73.67 \pm 7.00^{\mathrm{ab}}$ \\
Acrosome integrity (\%) $^{\mathrm{d}}$ & $69.50 \pm 0.96^{\mathrm{d}}$ & $83.50 \pm 2.99^{\mathrm{bc}}$ & $90.50 \pm 1.50^{\mathrm{a}}$ & $78.50 \pm 1.89^{\mathrm{c}}$ & $88.50 \pm 1.26^{\mathrm{ab}}$ \\
Membrane integrity (\%) & $83.50 \pm 1.89^{\mathrm{bc}}$ & $81.50 \pm 1.26^{\mathrm{c}}$ & $86.50 \pm 0.96^{\mathrm{ab}}$ & $89.50 \pm 1.26^{\mathrm{a}}$ & $75.50 \pm 1.71^{\mathrm{d}}$ \\
MDA (nmol/ml) & $0.04 \pm 0.00^{\mathrm{c}}$ & $0.02 \pm 0.00^{\mathrm{d}}$ & $0.06 \pm 0.00^{\mathrm{b}}$ & $0.01 \pm 0.00^{\mathrm{e}}$ & $0.09 \pm 0.00^{\mathrm{a}}$ \\
Sperm abnormality (\%) & $1.17 \pm 0.08^{\mathrm{a}}$ & $0.83 \pm 0.17^{\mathrm{ab}}$ & $0.58 \pm 0.22^{\mathrm{b}}$ & $0.83 \pm 0.17^{\mathrm{ab}}$ & $0.75 \pm 0.14^{\mathrm{ab}}$
\end{tabular}

${ }_{\mathrm{a}, \mathrm{b}, \mathrm{c}, \mathrm{d}, \mathrm{e}}$ Values within the same row with different superscripts differ significantly $(\mathrm{P}<0.05)$; SEM $=\mathrm{Standard}$ Error of mean; TEY = Tris egg yolk; TEYPO = Tris egg yolk pineapple and orange juices; TEYPC = Tris egg yolk pineapple and cucumber juices; TEYOC = Tris egg yolk orange and cucumber juices; TEYPOC = Tris egg yolk pineapple, orange and cucumber juices; MDA = Malondialdehyde.

\section{Discussion}

The supplementation of the extenders with fruit-juices improved the motility of buck spermatozoa after cryopreservation. The greater number of motile spermatozoa in semen samples cryopreserved with orange and pineapple juices compared to the control group indicated that these fruit-juices have the ability to sustain progressive motility. The improvement in this parameter could be attributed to the presence of substances in these fruits such as vitamins and phenolic compounds known to function as antioxidants (Gebhardt and Thomas, 2002; Kiwon et al., 2003; Cutler et al., 2008). Gardner et al. (2000) had earlier reported that concentrations of vitamin and total phenolic contents in fruit-juices have a strong relationship with antioxidant capacity. Ferulic acid is a major phenolic compound in fruits (Augustin and Williams, 2000), which neutralizes free radicals known as superoxide, hydroxyl radical and nitric oxide. In addition, ferulic acid acts synergistically with other antioxidants to reduce free radical damage to cell membranes (Zuo et al., 2002). The results of this study agreed with Reza et al. (2011), who states that antioxidant supplementation in stored semen improved motility of spermatozoa.

Furthermore, fruits are rich in sugars (Hulme, 1970), and goat sperm readily utilizes sugars for respiration. Sugars also provide osmotic balance and cryoprotection for sperm cells (Aboagla and Terada, 2004). The results further agreed with Fukuhara and Nishikawa (1973), who supported the role of sugar in semen diluents to provide energy and protection to sperm cells. Moreover, in the present study, the concentrations of fruit-juices used might have been optimum for preserving buck sperm progressive motility, as effects of orange and pineapple juices in particular varied with levels of supplementation in the extenders. Sperm progressive motility was better maintained at concentrations of $10 \%$ pineapple juice, 7.5 and $10 \%$ orange juice and with different combinations of fruit-juices compared to the control.

In this study, the improved percentage of acrosome integrity and membrane integrity in fruit-juice extenders after cryopreservation compared to the control indicated the beneficial effects of these extenders on these parameters. In line with Cummins and Yanagimachi (1986) and Drobnis et al. (1988), the improvement in sperm viability parameters after cryopreservation with fruit-juices observed in this study suggested protective effects of these juices and could be used for successful cryopreservation of spermatozoa. The improved motility, acrosome and membrane integrities coupled with reduced abnormality further supported the protective effects of the extenders supplemented with fruit-juices on viability of the sperm cells of WAD goat buck semen. The lower percentage of spermatozoa abnormality coupled with reduced concentration of MDA observed in the extenders supplemented with the fruit-juices compared to control after cryopreservation suggested that supplementation with these fruit-juices had beneficial effects on sperm morphology. The beneficial effects of the semen extenders supplemented with these fruit-juices on these parameters during cryopreservation compared to control group observed in this study further supported the roles of natural antioxidants and sugars in these fruits as chemo-preventive agents against oxidative damage and energy sources for the sperm cells (Kiwon et al., 2003; Spanos and Wrolstad, 2004; Reza et al., 2011). The finding corroborated a previous report that antioxidative compound was beneficial for sperm viability and 
reduction of lipid peroxidative damage to sperm membranes (Zheng and Zhang, 1997). The antioxidant potential of these fruit-juices with its structural characteristics of unsaturated side chain that has the ability to form resonance stabilized radicals (Marimuthu et al., 2007), coupled with the sugar content that provide energy, osmotic balance and cryoprotection (Aboagla and Terada, 2004) may explain the current findings of improved progressive motility, acrosome and membrane integrity, lower abnormalities and reduced MDA when these fruit-juices were added to the extenders.

In conclusion, the findings revealed that extenders supplemented with orange and pineapple at $10 \%$ consistently improved motility, acrosome integrity and membrane integrity, and reduced sperm abnormality compared to the control while no particular combination of these fruit-juices was consistently superior in all the parameters. Further studies of different combinations of the fruit-juices with higher levels of the juices are therefore necessary to ascertain the ideal combination for all the parameters.

\section{Acknowledgments}

The Research was fully funded by the Federal University of Agriculture in Abeokuta, Nigeria through the Directorate of Grant Management (DGM) of the University under the grant number FUNAAB-DGM/ 01-2012.

\section{References}

Aboagla EME, Terada T. 2004. Effects of egg yolk during the freezing step of cryopreservation on the viability of goat spermatozoa. Theriogenology, 62:11601172.

Adeyemo OK, Adeyemo OA, Oyeyemi MO, Agbede SA. 2007. Effect of semen extenders on the motility and viability of stored African Catfish (Clarias gariepinus) spermatozoa. J Appl Sci Environ Manag, 11:13-16.

Ahmad Z, Anzar M, Shahab N, Ahmad S, Andrabi MH. 2003. Sephadex and sephadex ionexchange filtration improves the quality and freezability of lowgrade buffalo semen ejaculates. Theriogenology, 59:1189-1202.

Al-Daraji HJ. 2012. Effect of diluents supplementation with different levels of orange juice on semen quality during liquid storage of roosters' semen. Int $J$ Vet Sci, 1:5-9.

Augustin S, Williams G. 2000. Dietary intake and bioavailability of polyphenols. J Nutr, 130:2073-2085.

Bearden HJ, Fuquay JW. 1997. Semen evaluation. In: Bearden HJ, Fuquay JW. Applied Animal Reproduction. 4th ed. Upper Saddle River, NJ: Prentice Hall. pp. 158169.

Bilodeau JF, Blanchette S, Cormier N, Sirad MA. 2002. Reactive oxygen species-mediated loss of bovine sperm motility in egg yolk Tris extender: protection by pyruvate, metal chelators and bovine liver or oviductal fluid catalase. Theriogenology, 57:1105-1112.

Bucak MN, Tekin N. 2007. Protective effects of taurine, glutathione and trehalose on the liquid storage of ram semen. Small Rumin Res, 73:103-108.

Cao G, Sofic E, Prior RL. 1996. Antioxidant capacity of tea and common vegetables. J Agric Food Chem, 44:3426-3431.

Cummins JM, Yanagimachi R. 1986. Development of ability to penetrate the cumulus oophorus by hamster spermatozoa capacitated in vitro, in relation to the timing of the acrosome reaction. Gamete Res, 15:187-212.

Cutler GJ, Nettleton JA, Ross JA. 2008. Dietary flavonoid intake and risk of cancer in postmenopausal women: The Iowa Women's Health Study. Int J Cancer, 123:664-671.

Daramola JO, Adekunle EO. 2015. Preservative effects of pineapple and cucumber juices on viability of refrigerated spermatozoa of the West African Dwarf bucks. Pertanika J Trop Agric Sci, 38:347-360.

Daramola JO, Adeloye AA. 2009. Physiological adaptation to the humid tropics with special reference to the West African Dwarf (WAD) goat. Trop Anim Health Prod, 41:1005-1016.

Donghue AM, Donoghue DJ. 1997. Effects of water and lipid soluble antioxidants on turkey sperm in vitro do not improve human sperm motility. Fertil Steril, 72:484-486.

Drobnis E, Yudin A, Cherr G, Katz D. 1988. Hamster sperm penetration of the zona pellucida: kinematic analysis and mechanical implications. Dev Biol, 130:311-323.

Duncan BD. 1955. Multiple Range Test and Multiple F-test. Biometrics, 11:1-42.

Fukuhara R, Nishikawa Y. 1973. Effects of various substrates on respiration, glycolysis and motility of goat spermatozoa. Jpn J Zoot Sci, 44:271-274.

Gardner PT, Tamsin TC, White AC, Mcphail DB, Duthie GP. 2000. The relative contributions of vitamin $\mathrm{C}$, carotenoids and phenolics to the antioxidant potential of fruit-juices. Food Chem, 68:471-474.

Gebhardt SE, Thomas RG. 2002. Nutritive Value of Foods. Beltsville, MD: USDA, Agriculture Research Service. 104 pp. (Home and Garden Bulletin, 72).

Hulme AC. 1970. The Biochemistry of Fruits and their Products. London: Academic Press. 147 pp.

Jeyendran RS, Van der ven HH, Peter-perez M, Crabo BG, Zaneveld LJ. 1984. Development of an assay to assess the functional integrity of the human sperm membrane and its relationship to other semen characteristics. J Reprod Fertil, 70:219-28.

Kiwon L, Yong JK, Hyong JL, Chang YL. 2003. Cocoa has more phenolic phytochemicals and a higher antioxidant capacity than teas and red wine. J Agric Food Chem, 51:7292-7295.

Krzyzosiak J, Evenson D, Pitt C, Jost L, Molan P, Vishwanath R. 2000. Changes in susceptibility of bovine sperm to in situ DNA denaturation, during 
prolonged incubation at ambient temperature under conditions of exposure to reactive oxygen species and nuclease inhibitor. Reprod Fertil Dev, 12:251-261.

Larson RA. 1988. The antioxidants of higher plants. Phytochemistry, 4:969-978.

Lewis SEM, Sterling ESL, Young LS. 1997. Comparison of individual antioxidant of semen and seminal plasma in fertile and infertile men. Fertil Steril, 67:142-147.

Marimuthu S, Adluri RS, Venugopal PM. 2007. Ferulic acid: therapeutic potential through its antioxidant property. Clin J Biochem Nutr, 40:92-100.

Maxwell WMC, Salamon S. 1993. Liquid storage of ram semen. Reprod Fertil Dev, 5:613-638.

Ondei LS, Silveira LM, Leite AA, Souza DRS, Pinhel AAS, Percário S, Ricci O, Bonini-domingos CR. 2009. Lipid peroxidation and antioxidant capacity of G6PD-deficient patients with A- $(202 \mathrm{G}>\mathrm{A})$ mutation. Genet Mol Res, 8:1345-1351.

Purdy PH. 2006. A review on goat sperm cryopreservation. Small Rumin Res, 63:215-225.

Reza A, Razi J, Hossein T. 2011. Influence of added Vitamin $\mathrm{C}$ and Vitamin $\mathrm{E}$ on frozen-thawed bovine sperm cryopreserved in citrate and tris-based extenders. Vet Res Forum, 2:37-44.

Sanchez-partida LG, Setchell BP, Maxwell WMC.
1997. Epididymal compounds and antioxidants in extenders for the frozen storage of ram spermatozoa. Reprod Fertil Dev, 9:689-696.

Spanos GA, Wrolstad RE. 2004. Polyphenols: food sources and bioavailability. Am J Clin Nutr, 79:727-747. Velioglu YS, Mazza G, Gao L, Oomah BD. 1998. Antioxi-dant activity and total phenolics in selected fruits, vegetables, and grain products. J Agric Food Chem, 46:4113-4117.

Wang H, Cao G, Prior RL. 1996. Total antioxidant capacity of fruits. J Agric Food Chem, 44:701-705.

Watson PF. 1995. Recent developments and concepts in the cryopreservation of spermatozoa and the assessment of their post-thawing functions. Reprod Fertil Dev, 7:871-891.

Yagi K. 1998. Simple procedure for specific assay of lipid hydroperoxides in serum or plasma. Free Radic Antiox Protoc, 108:101-106.

Zheng RL, Zhang DL. 1997. Effects of ferulic acid on fertile and asthenozoospermic infertile human sperm motility, viability, lipid peroxidation and cyclic nueleotides. Free Radic Biol Med, 22:58.

Zuo Y, Wang C, Zhang H. 2002. Separation, characterization and quantitation of benzoic and phenolic antioxidant in American Cranberry fruit by GC-MS. J Agric Food Chem, 50:3789-3794. 